\title{
Talcosis in soapstone artisans: High-resolution CT findings in 12 patients
}

\author{
H. Pereira Faria ${ }^{\mathrm{a}, \mathrm{b}}, *$, A. de Souza Veiga ${ }^{\mathrm{b}}$, L. Coutinho Teixeira ${ }^{\mathrm{b}}$, \\ O.M. de Paula Alves Bezerra ${ }^{\text {b }}$, A.P. Scalia Carneiro ${ }^{c}$, C.S. Ferreira ${ }^{d}$, \\ E. Marchiori ${ }^{\mathrm{e}}$ \\ ${ }^{a}$ Department of Anatomy and Image, Federal University of Minas Gerais, Minas Gerais, Brazil \\ ${ }^{\mathrm{b}}$ School of Medicine, Federal University of Ouro Preto, Minas Gerais, Brazil \\ ${ }^{\mathrm{c}}$ Reference Centre on Workers' Health, Clinical Hospital, Federal University of Minas Gerais, Minas Gerais, Brazil \\ ${ }^{\mathrm{d}}$ Diagnostic Centre, Clinical Hospital, Federal University of Minas Gerais, Minas Gerais, Brazil \\ e Department of Diagnostic Radiology, Federal University of Rio de Janeiro, Rio de Janeiro, Brazil
}

\section{ARTICLE INFORMATION}

Article history:

Received 28 July 2013

Received in revised form

28 October 2013

Accepted 30 October 2013
AIM: To describe the high-resolution computed tomography (HRCT) features of pneumoconiosis observed in soapstone artisans.

MATERIALS AND METHODS: The present study included 12 soapstone artisans with chest radiography abnormalities consistent with the diagnosis of pneumoconiosis, in accordance with the International Labour Office classification. All patients had undergone HRCT, and the images were retrospectively analysed by two chest radiologists, who reached decisions in consensus.

RESULTS: All patients presented with interlobular septal thickening. Small centrilobular nodules (75\%) and ground-glass opacities (67\%) were also common findings. The distributions of abnormalities were predominantly diffuse. No pleural abnormality was found.

CONCLUSION: The HRCT abnormalities observed in this group of soapstone artisans are similar to those of pure talc pneumoconiosis.

(C) 2013 The Royal College of Radiologists. Published by Elsevier Ltd. All rights reserved.

\section{Introduction}

Soapstone, a compact form of talcum powder, is composed of hydrated magnesium silicates, with an ideal composition of $63.5 \% \mathrm{SiO}_{2}, 31.7 \% \mathrm{MgO}$, and $4.8 \% \mathrm{H}_{2} \mathrm{O}{ }^{1}$ These silicate minerals are derived from metamorphic alteration of mineral rocks, sometimes including the amphibole and serpentine groups of asbestos, after their exposure to specific temperatures,

\footnotetext{
* Guarantor and correspondent: H. Pereira Faria, Federal University of Ouro Preto, Minas Gerais, Brazil and Department of Anatomy and Image, Federal University of Minas Gerais, Minas Gerais, Brazil. Rua José Gaspar de Araújo, 121 apto 302, Bairro Cidade Nova, BH, MG 31170-790, Brazil. Tel.: +55 31 91103612; fax: +55 3134520300 .

E-mail address: henryfaria@hotmail.com (H. Pereira Faria).
}

pressures, and circulating liquid solutions. ${ }^{2}$ Steatite has been widely employed in carved façade elements for historical buildings and baroque churches in Brazil since the 17th century. Brazilian artisans, especially those in Minas Gerais, currently use soapstone to produce a variety of items, such as statues, bowls, and souvenirs. ${ }^{3}$

The effects of talc dust on the health of miners and industrial workers have been studied. Due to the variable composition of talc, diverse patterns of pulmonary disease are associated with its inhalation. Three forms of talc pneumoconiosis caused by inhalation have been described: talc asbestosis, produced by the inhalation of talc with asbestiform fibres; talc silicosis, caused by the mining of talc with a high silica content; and talcosis, associated with the inhalation of pure talc. ${ }^{1,4,5}$ 


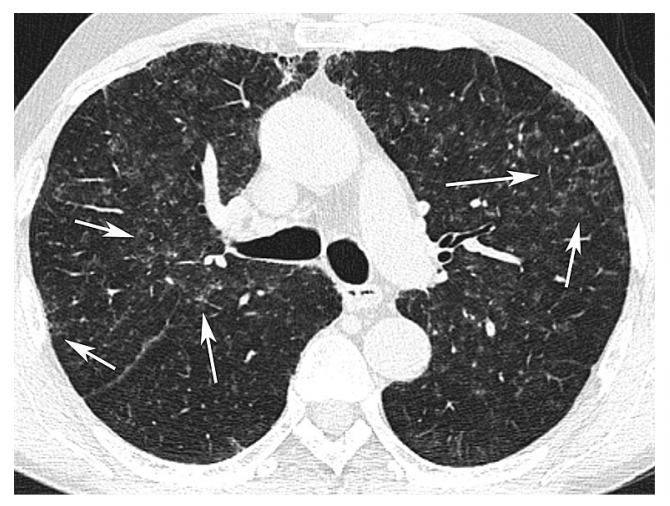

(a)

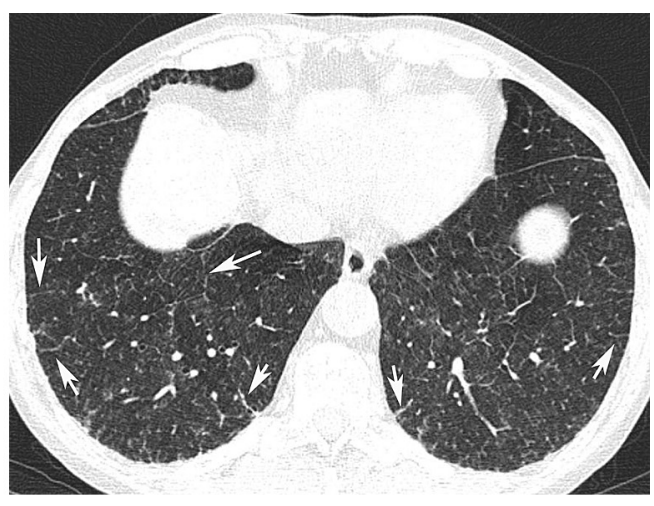

(b)

Figure 1 A 65-year-old male artisan with 15 years of occupational exposure to soapstone. (a) HRCT image at the level of bronchial bifurcation shows ground-glass opacities (arrows). (b) Image at the level of lower lung zones demonstrates interlobular septal thickening (arrows).

The high-resolution CT features of pure talcosis due to occupational exposure in secondary industries ${ }^{6,7}$ and intravenous administration ${ }^{8,9}$ have been reported. The present authors were unable to find a report of the highresolution computed tomography (HRCT) characteristics of talcosis due to soapstone exposure. Thus, the purpose of the present study was to describe the HRCT findings in 12 artisans who had been exposed occupationally to soapstone, and also exhibited chest radiographic abnormalities.

\section{Materials and methods}

Twelve patients with chest radiographic abnormalities were selected from 261 artisans in three districts of two historical towns (Ouro Preto and Mariana, Minas Gerais, Brazil) who had undergone chest radiography between 2000 and 2010. Eleven patients were male and one was female; their mean age was 50.6 (range 34-80) years. The mean duration of occupational exposure was 21.5 (range 10-40) years. Diagnoses of pneumoconiosis were based on patients' histories of prolonged exposure to soapstone dust and chest radiographs showing changes consistent with this disease, in accordance with the International Labour Office (ILO) classification. ${ }^{10}$ The ethics committee approved this study and all patients provided informed consent.

Radiographs from the 261 artisans were graded using the ILO system, and 12 artisans showing $\mathrm{x}$-ray profusion of $0 /$ $1-3 / 3$ were included in the study. In the ILO scoring system, profusion of small opacities is recorded on a 12-point incremental scale. Category 0 includes the scores of $0 /-, 0 / 0$, and $0 / 1$; category 1 includes $1 / 0,1 / 1$, and $1 / 2$; category 2 includes $2 / 1,2 / 2$, and $2 / 3$; and category 3 includes the scores of $3 / 2,3 / 3$, and $3 /+$. Two categories of shape (rounded and irregular) are recognized, and three sizes are differentiated for each shape. Small rounded opacities are denoted by the letters $p$ (diameters $\leq 1.5 \mathrm{~mm}$ ), $q$ (diameters of $1.5-3 \mathrm{~mm}$ ), and $r$ (diameters of 3-10 mm). Small irregular opacities are designated using the letters $s, t$, and $u$, with width categories corresponding to the diameters for small rounded opacities.
HRCT images of the 12 patients were obtained in the mediastinal (window width $400 \mathrm{HU}$; level $-40 \mathrm{HU}$ ) and lung (window width $1200 \mathrm{HU}$; level $-600 \mathrm{HU}$ ) window settings using the same dual-section CT machine (Somatom Spirit; Siemens Medical Solutions, Munich, Germany) with $1 \mathrm{~mm}$ thick sections at $10 \mathrm{~mm}$ intervals from the pulmonary apices to the bases. The CT images were reconstructed using a highfrequency reconstruction algorithm. Two chest radiologists who were blinded to the radiographic data reviewed the HRCT images independently, and final decisions were reached in consensus. The images were analysed to determine the location (upper, middle, or lower lung zone) and incidence of interlobular septal thickening, ground-glass opacities, subpleural lines, small nodules, intralobular lines, traction bronchiectasis, honeycombing, and emphysema. These parenchymal abnormalities were defined according to the Fleischner Society's glossary of terms. ${ }^{11}$

\section{Results}

All 12 artisans had interlobular septal thickening (Fig 1b), which was irregular in nine (75\%) and smooth in three (25\%) cases. Thickening was distributed in all lung zones in seven artisans and showed middle- and lower-zone predominance in four artisans. Lower-zone predominance was noted in one patient.

Small nodules were found in nine (75\%) patients and were predominantly centrilobular in eight artisans (Fig 2). In one artisan, the distribution of nodules was mainly random. Small rounded opacities involved all lung zones in eight artisans and showed middle- and lower-zone predominance in one patient.

The other frequent finding was ground-glass opacities, observed in eight (67\%) patients (Fig. 1a). These opacities were distributed in all lung zones in five artisans and had middle- and lower-zone predominance in three patients.

Conglomerate masses were detected in two cases and involved only the upper lobes. In one patient, soft-tissue windows demonstrated focal areas of high attenuation (Fig 3). Emphysema was found in two artisans, both of whom were smokers. No lymph node enlargement or pleural involvement was found. 


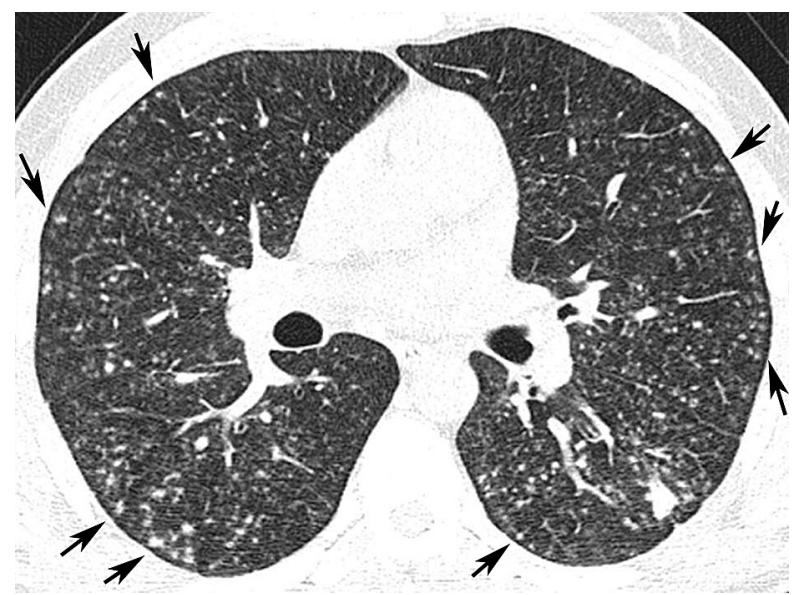

Figure 2 A 40-year-old male artisan with 18 years of occupational exposure to soapstone. HRCT image at the level of the upper right lung shows ill-defined small nodular opacities (arrows) with predominantly centrilobular locations.

\section{Discussion}

Soapstone contains variable amounts of talc and other minerals, such as chlorites, calcite, dolomite, magnesite, magnetite, pyrophyllite, and quartz. Asbestos may also be present as an accessory mineral in a product often referred to as asbestine talc. Tremolite and chrysotile, members of the amphibole and serpentine groups of asbestos, respectively, are the most common asbestos contaminants in industrial talc dust. The amount of quartz (free silica) varies and can be up to $20 \%$ in some samples. High-grade talc, used in health and cosmetic products, contains $>90 \%$ mineral talc, is free of detectable asbestos, and is contaminated by only limited amounts of other minerals., ${ }^{1,2}$

Exposure to talc may occur during production, which includes mining and milling; in secondary industries, such as rubber and ceramic industries; and in the handling of final products, such as cosmetic talc. ${ }^{1}$ All of the present patients had histories of occupational exposure to talc dust during the production of artistic artefacts, such as statues, bowls, and souvenirs.
The accurate mineralogical identification of fibres or other mineral contaminants is essential to determine the exact composition of a talc dust. All of the present patients were from three districts located very close to one another. In one of these districts, Bezerra et al. $^{3}$ performed a qualitative and quantitative study of inhaled dust that demonstrated the presence of breathable tremolite-actinolite fibres among the talc particles. Free crystalline silica was not identified. A mineral analysis of soapstone residue in these three districts identified talc, tremolite-actinolite, chloriteserpentine, nimite, ilmenite, dolomite, magnetite, and magnesite. ${ }^{12}$ Although early studies of talc pneumoconiosis $^{13-15}$ were unable to determine whether the clinical, pathological, and radiographic manifestations observed were caused by talc per se or by the association with asbestiform fibres, subsequent works demonstrated that talc associated with non-asbestiform silicates or containing only traces of asbestiform minerals was considered to be virtually pure. ${ }^{5,16}$ Thus, the manifestations observed in the present patients were caused specifically by talc.

Marchiori et al. ${ }^{7}$ described HRCT findings in three patients who were exposed to talc through a secondary industry (talc factory; $n=2$ ) and handling of a final product (cosmetic talc; $n=1$ ). The main abnormalities consisted of small centrilobular and subpleural nodules in all lung zones, associated with heterogeneous conglomerated masses and focal ground-glass opacities. Akira et al. ${ }^{6}$ reported radiographic and HRCT findings in 14 patients with pathological evidence of talc pneumoconiosis. Twelve patients worked in secondary industries (talc factory and rubber industry) and two handled final products (cosmetic talc and confectionery). The main high-resolution CT findings were diffuse small centrilobular nodules and septal thickening. Other recurrent findings included large opacities, subpleural lines, lymph node enlargement, and ground-glass opacities. Pleural plaque was found in $50 \%$ of cases.

In the present cases, the predominant HRCT abnormalities were irregular interlobular septal thickening and small centrilobular nodules affecting all lung zones. Other studies $^{6,7}$ have reported similar findings. However, large opacities were found in only two cases and lymph node enlargement, a common finding in silicosis, ${ }^{17}$ was not found.

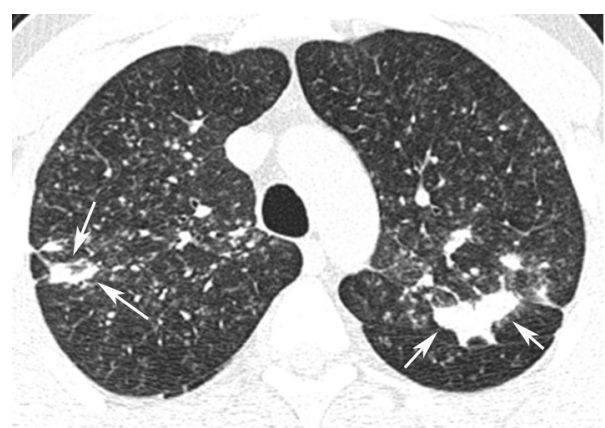

(a)

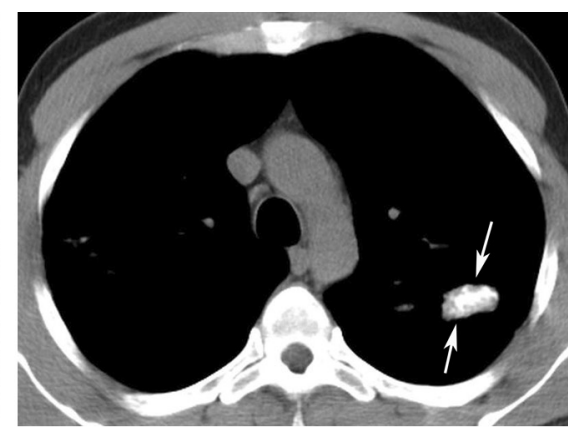

(b)

Figure 3 A 34-year-old male artisan with 20 years of occupational exposure to soapstone. (a) HRCT image at the level of the upper lobes demonstrates bilateral small nodules with a predominantly centrilobular distribution and conglomerate masses (arrows). (b) Mediastinal window images taken at the same level as (a) demonstrate high attenuation within the conglomerate left lung mass. 
Pleural plaque was not seen in any case, and no evidence of pleural effusion was detected. These abnormalities are common manifestations of asbestos exposure. ${ }^{18,19}$ Feigin $^{5}$ reviewed 18 radiographic findings of talc exposure that had been documented by pathological analysis of the mineral within the lung. Talc alone caused no pleural change, and radiographic abnormalities consisted of small nodules and reticulations in all lung zones. These results are in accordance with the imaging findings from the present patients.

The present study has several limitations. It was retrospective and included a small number of patients. Although diagnoses were based on well-defined criteria, the lack of histopathological data prevented correlation between HRCT and histopathological findings. However, the present analysis met the aim of the study, to describe the HRCT findings of pneumoconiosis in soapstone artisans.

In conclusion, the main HRCT abnormalities observed in soapstone artisans with pneumoconiosis were irregular interlobular septal thickening, centrilobular nodules, and ground-glass opacities. The predominant distribution of abnormalities was diffuse. No pleural abnormality was found.

\section{References}

1. Gibbs AE, Pooley FD, Griffiths DM, et al. Talc pneumoconiosis: a pathologic and mineralogic study. Hum Pathol 1992;23:1344-54.

2. Hildick-Smith GY. The biology of talc. Br J Ind Med 1976;33:217-29.

3. Bezerra OM, Dias EC, Galvão MA, et al. Talc pneumoconiosis among soapstone handicraft workers in a rural area of Ouro Preto, Minas Gerais Brazil. Cad Saúde Pública 2003;19:1751-9.

4. Lockey JE. Nonasbestos fibrous minerals. Clin Chest Med 1981;2:203-18.
5. Feigin DS. Talc: understanding its manifestations in the chest. AJR Am J Roentgenol 1986;146:295-301.

6. Akira M, Kozuka T, Yamamoto S, et al. Inhalation talc pneumoconiosis: radiographic and CT findings in 14 patients. AJR Am J Roentgenol 2007; 188:326-33.

7. Marchiori E, Souza Júnior AS, Müller NL. Inhalational pulmonary talcosis: high-resolution CT findings in 3 patients. J Thorac Imaging 2004; 19:41-4.

8. Ward S, Heyneman LE, Reittner P, et al. Talcosis associated with IV abuse of oral medications: CT findings. AJR Am J Roentgenol 2000;174:789-93.

9. Padley SP, Adler BD, Staples CA, et al. Pulmonary talcosis: CT findings in three cases. Radiology 1993;186:125-7.

10. International Labour Office. Guidelines for the use of ILO international classification of radiographs of pneumoconiosis. Geneva: ILO; 1980. p. $1-48$.

11. Austin JH, Müller NL, Friedman PJ, et al. Glossary of terms for CT of the lungs: recommendations of the nomenclature committee of the Fleischner Society. Radiology 1996;200:327-31.

12. Rodrigues ML, Lima RM. Purification of the soapstone residues, produced in artisan workshops, by flotation and chemical leaching. Rem: Rev Esc Minas 2011;64:353-7.

13. Porro FW, Patton JR, Hobbs AA. Pneumoconiosis in the talc industry. AJR Am J Roentgenol 1942;47:507-24.

14. McLaughlin AI, Rogers E, Dunham KC. Talc pneumoconiosis. Br J Ind Med 1949;6:184-93.

15. Siegal W, Smith AR, Greenburg L. The dust hazard in tremolite talc mining, including roentgenological findings in talc workers. AJR Am J Roentgenol 1943;49:11-29.

16. Vallyathan NV, Green FH, Craighead JE. Recent advances in the study of mineral pneumoconiosis. Pathol Annu 1980;15:77-104.

17. Kim KI, Kim CW, Lee MK, et al. Imaging of occupational lung disease. RadioGraphics 2001;21:1371-91.

18. Chong S, Lee KS, Chung MJ, et al. Pneumoconiosis: comparison of imaging and pathologic findings. RadioGraphics 2006;26:59-77.

19. Roach HD, Davies GJ, Attanoos R, et al. Asbestos: when the dust settles - an imaging review of asbestos-related disease. RadioGraphics 2002;22:S167-84. 